\title{
Nosocomial bacterial pneumonia in human immunodeficiency virus infected subjects: incidence, risk factors and outcome
}

\author{
M. Tumbarello*, E. Tacconelli*, K. de Gaetano Donati*, S. Bertagnolio*, M. Cataldo*, \\ T. Pirronti" ${ }^{\#}$ F. Ardito", R. Cauda*
}

\begin{abstract}
Nosocomial bacterial pneumonia in human immunodeficiency virus infected subjects: incidence, risk factors and outcome. M. Tumbarello, E. Tacconelli, K. de Gaetano Donati, S. Bertagnolio, M. Cataldo, T. Pirronti, F. Ardito, R. Cauda. C) ERS Journals Ltd 2001.

ABSTRACT: The presented study examined the incidence, risk factors and outcome of nosocomial bacterial pneumonia (NBP) in human immunodeficiency virus (HIV)infected subjects. Forty-two cases of NBP were ascertained by a 5-yr prospective surveillance and were matched to 84 controls. NBP incidence was 10.8 per 10,000 hospital patient-days. In particular, the incidence of NBP was 13.9 per 10,000 patientdays in the period 1994-1996 and 5.6 per 10,000 patient-days in the period 1997-1998 $(\mathrm{p}=\mathbf{0 . 0 1})$.

By using regression analysis, predictors for developing NBP were an increasing value of Acute Physiology and Chronic Health Evaluation (APACHE) III score $(\mathbf{p}<0.01)$ and the presence of acquired immune deficiency syndrome (AIDS)-related central nervous system $(\mathrm{CNS})$ diseases $(p=0.01)$. The additional hospital stay attributable to NBP was 15 days. The attributable mortality rate was estimated to be $29 \%$.

Nosocomial bacterial pneumonia is more common in patients with advanced human immunodeficiency virus infection, high Acute Physiology and Chronic Health Evaluation III score and central nervous system diseases. Although the incidence of nosocomial bacterial pneumonia, as well of other opportunistic infections, decreased considerably in the era of highly active antiretroviral therapy, it still represents an important cause of mortality.
\end{abstract}

Eur Respir J 2001; 17: 636-640.

\author{
Depts of *Infectious Diseases, ${ }^{\#}$ Radio- \\ logy and "Microbiology, Catholic Uni- \\ versity, Rome, Italy. \\ Correspondence: M. Tumbarello \\ Istituto Malattie Infettive \\ Università Cattolica \\ Largo A. Gemelli 8 \\ 00168 Roma \\ Italy \\ Fax: 39063054519
}

Keywords: Acquired immune deficiency syndrome

human immunodeficiency virus nosocomial bacterial pneumonia risk factors

Received: June 62000

Accepted after revision September 19 2000
The impact of nosocomial infections on morbidity and mortality of hospitalized patients is still a relevant issue and an important topic of discussion for physicians and epidemiologists at the beginning of the new millennium. Unfortunately, the prevention of hospitalacquired infections has proven to be difficult and consequently, the incidence rates of some nosocomial infections may be increasing [1-4]. According to the surveillance data from the Centers for Disease Control and prevention (CDC), overall, pneumonia is the second most common nosocomial infection, occurring in 7.7 of 1,000 discharged patients [5]. In human immunodeficiency virus (HIV)-infected subjects, bacterial pneumonia is responsible for significant morbidity [6-8] and, although most episodes are community-acquired, nosocomial episodes are also not infrequently observed [9-11]. It is also noted that, although the incidence of nosocomial bacterial pneumonia (NBP), as well as other opportunistic infections [12] has decreased considerably in the era of highly active antiretroviral therapy (HAART), NBP still represents an important cause of mortality [13]. However, to the best of the authors' knowledge, few reports have focused on NBP in such patients. Hence, the objectives of this 5-yr prospective, matched, case-control study were the following: 1) to analyse the impact of length of hospital stay on the development of NBP using the "daily infection rate" computed according to CD4+ lymphocyte cell count and HIV viraemia; 2) to define risk factors for NBP using a statistical approach that limits confounding factors; and 3) to compute the additional hospitalization and mortality associated with NBP.

\section{Methods}

\section{Patient population}

From January 1994 until December 1998, all HIVinfected subjects with NBP in the Department of Infectious Diseases of a 1,700-bed university hospital located in Rome, Italy, were eligible for inclusion in the study. None of the patients were receiving mechanical ventilation with tracheal incubation prior to inclusion in the study. The CDC definition for NBP was used, with the modification that an abnormal chest radiograph was also required [14]. The bacterial aetiology of pneumonia, in patients who had negative microbiological analysis for other significant pathogens including Mycobacterium, Pneumocystis carinii and fungi, was based on at least one of the following: 1) isolation of bacteria in purulent sputum (two or more samples) and/ 
or in bronchoalveolar lavage (BAL) and/or in blood; 2) successful treatment of pneumonia with antibacterial drugs (with the exception of subjects who underwent empirical treatment with trimethoprim-sulphamethoxazole); 3) autopsy evidence of bacterial pneumonia.

\section{Study design}

A matched case-control study was performed. All HIV-infected subjects who had NBP were enrolled prospectively in the study and designated as "cases" and those without pneumonia as "controls". Each case was matched with two controls. The matching criteria included the following: age $( \pm 5 \mathrm{yrs})$; sex; cause of hospital admission; number of peripheral T CD4+ cells $\left( \pm 50 \cdot \mathrm{mm}^{-3}\right)$; hospitalization in the same ward within six weeks of diagnosis of the matched case; no evidence of nosocomial infection and a duration of hospitalization similar to the period from admission to infection in the cases $( \pm 20 \%)$.

The following data were obtained from cases and controls: age, sex, NBP risk factors, concurrent opportunistic infections, total length of hospitalization, previous antimicrobial therapy, number of antibiotics or other medications (antivirals, corticosteroids, antacids) and duration of the therapy, nutritional status, HIVrisk behaviour, stage of HIV infection [15], previous manifestations of HIV infection, date of acquired immune deficiency syndrome (AIDS)-defining condition, type and use of prophylaxis for $P$. carinii pneumonia (PCP) and antiretroviral therapy, Karnofsky performance score, Acute Physiology and Chronic Health Evaluation (APACHE) III score [16], and vital signs. Data collected from the initial laboratory records included: numbers of circulating $\mathrm{T}$ CD4+ and peripheral polymorphonuclear (PMN) cells $\cdot \mathrm{mm}^{-3}$, HIV viraemia (copies $\cdot \mathrm{mL}^{-1}$ ), serum lactate dehydrogenase and arterial blood gas levels. Neutropenia was defined as a concentration of circulating PMNs $<1,000 \cdot \mathrm{mm}^{3}$. In patients with pneumonia, the following were also considered: aetiological agents, clinical features, management, outcome and cause of death as listed by the attending physicians.

\section{Microbiological evaluation}

Sputum samples with $>10$ epithelial cells or $<25$ neutrophils per high power field were considered contaminated with oropharyngeal flora. BAL fluid was considered adequate for microbiological evaluation if alveolar macrophages were identified in the specimen. The threshold concentration required for micro-organisms isolated from the BAL was $\geqslant 10^{3}$ colony forming units $(\mathrm{CFU}) \cdot \mathrm{mL}^{-1}$.

\section{Statistics}

Quantitative variables were tested for normal distribution and compared by means of a two tailed unpaired t-test. Differences in group proportions were assessed by use of the Chi-squared test and Fisher's exact test.
The "daily infection rate" describes the total number of infections divided by the total number of hospital days. In calculating the denominator of this equation, the date of admission was considered to be the first day at risk; the date of discharge or death, the last. Considering that all hospital days may not necessarily provide the same degree of risk to individual patients according to the different stage of HIV infection, the rate of infection was calculated for various hospital days. After the first day of hospital stay, days were subgrouped into 3-day periods.

Multivariate analysis was performed, using logistic regression models while $95 \%$ test based confidence intervals $(95 \% \mathrm{CI})$ were used to determine the statistical significance of the odds ratio (OR). A limited number of variables which were found to be significant at the $\mathrm{p}<0.05$ level on univariate analysis were included in the logistic regression models to define independent predictors of NBP. In the primary model, all chosen variables were entered simultaneously. A second model was constructed using stepwise entry of the same variables. The "attributable mortality rate" for NBP was defined as the excess mortality due to NBP and it was determined by subtracting the crude (overall) mortality rate of the controls from that of the cases.

All statistical analyses were performed using the software program EGRET (Statistics and Epidemiology Research Corporation, Seattle, WA, USA).

\section{Results}

\section{Incidence}

Forty-five incident cases were initially recorded during this 5-yr period. Three cases were excluded because of incomplete medical records. The remaining 42 constitute the total number of cases. Table 1 summarizes the population data under study.

During the study, the hospital-wide incidence of NBP, in HIV-infected subjects, was 10.8 per 10,000 patient-days. No distinct clusters or outbreaks of NBP occurred during the study period. In particular, the incidence was 13.9 per 10,000 patient-days 1994-1996, while after the introduction of HAART (September 1996 in Italy) the incidence was significantly reduced to 5.9 per 10,000 patient-days $(\mathrm{p}=0.01)$. Consequently, the risk ratio for NBP per patient day in the HAART era was $0.39(95 \% \mathrm{CI}=0.17-0.86)$.

Figure 1 shows the number of NBP per 10,000 patient-days according to the hospital day, at risk for infection and to the number of peripheral T CD4+ cell count $\cdot \mathrm{mm}^{-3}$. Between days 2 and 4 , patients with a low number of $\mathrm{T}$ CD4+ cells $\left(<100 \cdot \mathrm{mm}^{-3}\right.$; group 1$)$ experienced two NBP per 10,000 person-days compared to 1.8 infections in patients with a higher $\left(>100 \cdot \mathrm{mm}^{-3}\right)$ number of T CD4+ cells (group 2), $(\mathrm{p}=\mathrm{NS}$; group 1 versus group 2). For each subsequent period of time, patients in group 2 experienced fewer NBP per patient day compared to group $1(\mathrm{p}<0.01$; Chi-squared for trend). Similar results were observed after stratifying by HIV viraemia $(\mathrm{p}<0.01$; Chi-squared for trend, when considering only those subjects observed after 1996). 
Table 1. - Demographic data of 42 human immunodeficiency virus (HIV)-infected patients with nosocomial bacterial pneumonia (NBP) (cases) and 84 matched HIV-infected patients without nosocomial infections (controls)

\begin{tabular}{|c|c|c|}
\hline & Cases & Controls \\
\hline $\operatorname{Sex} M / F$ & $31 / 11$ & $62 / 22$ \\
\hline Mean age yrs & $34.1 \pm 6.2$ & $33.3 \pm 4.4$ \\
\hline \multicolumn{3}{|l|}{ HIV risk behaviour \% } \\
\hline Intravenous drug abuse & $26(62)$ & $56(67)$ \\
\hline Homosexual contacts & $8(19)$ & $14(17)$ \\
\hline Heterosexual contacts & 7 (17) & $12(14)$ \\
\hline Other & $1(2)$ & $2(2)$ \\
\hline \multicolumn{3}{|l|}{ Stage of HIV infection* \% } \\
\hline A & $2(5)$ & $5(6)$ \\
\hline B & $5(12)$ & $10(12)$ \\
\hline $\mathrm{C}$ & $35(83)$ & $69(82)$ \\
\hline \multicolumn{3}{|l|}{ Main reason for admission $\%$} \\
\hline Gastrointestinal manifestations & $14(33)$ & $28(33)$ \\
\hline Neurological syndromes & $12(29)$ & $24(29)$ \\
\hline Fever of unknown origin & $10(24)$ & $20(24)$ \\
\hline Neoplastic diseases & $6(14)$ & $12(14)$ \\
\hline Mean hospital stay days & $30.1 \pm 10.1$ & $15 \pm 4.9$ \\
\hline Mean days to NBP & $14.3 \pm 19.6$ & \\
\hline Mean PMN cells $\cdot \mathrm{mm}^{-3}$ & $1278 \pm 1050$ & $3278 \pm 1670$ \\
\hline Mean T CD4+ cells $\cdot \mathrm{mm}^{-3}$ & $87.3 \pm 49.5$ & $94.1 \pm 56.2$ \\
\hline Mean HIV-RNA ${ }^{\#} \mathrm{cp} \cdot \mathrm{mL} \times 10^{3}$ & $35.8(0.5-650.5)$ & $29.5(0.5-475.5)$ \\
\hline PCP prophylaxis with CTX \% & $35(83)$ & $62(74)$ \\
\hline \multicolumn{3}{|l|}{ Antiretroviral therapy $\%$} \\
\hline Monotherapy & $13(31)$ & $18(21)$ \\
\hline 2 RTI & $19(45)$ & $34(41)$ \\
\hline HAART & $6(14)$ & $23(27)$ \\
\hline No therapy & $4(10)$ & $9(11)$ \\
\hline
\end{tabular}

Data are presented as mean $\pm \mathrm{SD}, \mathrm{n}(\%)$, or mean (range). *: According to Centers for Disease Control definition of acquired immunodeficiency syndrome; ${ }^{\#}$ : available after September 1996. cp: copies; CTX: cotrimoxazole; RTI: reverse transcriptase inhibitor; HAART: highly active antiretroviral therapy; PMN: polymorphonuclear; RNA: ribonucleic acid; PCP: Pneumocystis carinii; CTX: cotrimoxazole.

\section{Risk factors}

A comparison of the cases and controls showed differences in the distribution of known and potential risk factors. The value of the APACHE III score $(\mathrm{OR}=3.41 ; \mathrm{p}<0.01$, Chi-squared for trend $)$, presence of

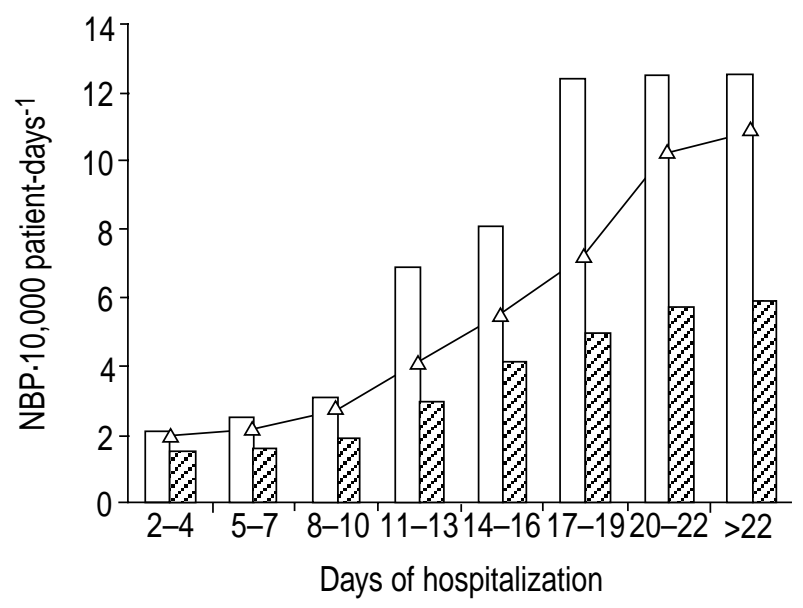

Fig. 1. - Daily rate of nosocomial bacterial infection (NBP) in human immunodeficiency virus-infected subjects according to days of hospitalization and number of peripheral T CD4+ lymphocy-

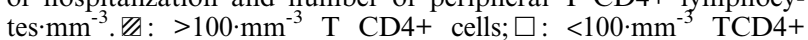
cells. The line represents the mean number of NBP episodes.
AIDS-related central nervous system (CNS) diseases $(\mathrm{OR}=4.11 ; 95 \% \mathrm{CI}=1.51-11.34 ; \mathrm{p}=0.003)$, use of total parenteral nutrition $(\mathrm{OR}=3.25 ; 95 \% \mathrm{CI}=1.34-7.92 ; \mathrm{p}=$ $0.006)$, neutropenia $(\mathrm{OR}=3.54 ; 95 \% \mathrm{CI}=1.06-12.37$; $\mathrm{p}=0.01)$, low $\left(<2 \mathrm{~g} \cdot \mathrm{dL}^{-1}\right)$ albumin level $(\mathrm{OR}=2.81 ; 95 \%$ $\mathrm{CI}=1.20-6.60 ; \mathrm{p}=0.01)$, and previous antibiotic therapy $(\mathrm{OR}=2.75 ; 95 \% \mathrm{CI}=1.19-6.38 ; \mathrm{p}=0.01)$, were each significantly different in the two groups of patients.

The clinically relevant conditions and treatments most strongly associated with NBP were further analysed using logistic regression. An increasing APACHE III score $(\mathrm{OR}=3.01 ; 95 \% \mathrm{CI}=1.25-7.24 ; \mathrm{p}<0.01)$, and the presence of AIDS-related CNS diseases $(\mathrm{OR}=2.25$; $95 \% \mathrm{CI}=1.07-4.73$; $\mathrm{p}=0.01$ ) were found to be independent predictors of NBP. Stepwise entry of the variables into the model yielded similar results. Neutropenia was the only other risk factor that approached significance $(p=0.06)$. The other potential predictors, i.e. previous antibiotic therapy, low albumin level, use of parenteral nutrition, were no longer implicated as risk factors for NBP in the study group after controlling for the two strongest predictors.

\section{Clinical and radiological features}

The more common presenting symptoms of pneumonia were: fever $(93 \%)$, cough $(86 \%)$ with $(78 \%)$ or without $(22 \%)$ expectoration, dyspnoea $(48 \%)$, and 
chest pain $(19 \%)$. The presenting radiological manifestations of bacterial pneumonia were monolateral alveolar infiltrates in 31 episodes $(74 \%)$ and bilateral alveolar infiltrates in 11 episodes $(26 \%)$. Pleural effusion was present in six cases (14\%), and empyema in two of the previous ones.

\section{Microbial aetiology}

A bacterial pathogen was isolated from purulent sputum in 25 patients with NBP (59\%), and from BAL in three patients $(7 \%)$. Blood cultures were positive in 10 patients $(24 \%)$. Gram-negative bacteria were responsible for 18 episodes of NBP (43\%), Grampositive bacteria for eight episodes $(19 \%)$. Mixed flora were isolated in two patients $(5 \%)$. No organism was isolated in 14 patients $(33 \%)$ (table 2). Three patients had methicillin-resistant Staphylococcus aureus pneumonia (3 of $7 ; 43 \%$ ).

\section{Outcome}

The mean \pm SD length of total hospitalization was $30 \pm$ 10 days for the cases in comparison to a mean of $15 \pm 4$ for the controls. The mean excess length of hospital stay attributable to NBP was 15 days and the overall excess length of hospitalization attributable to these infections was 1,213 days, for the whole study period.

All patients received antibiotic therapy which was initially established according to the most likely aetiological agent and later modified, if necessary, when the in vitro susceptibility of the isolate became known. Five out of 42 patients required mechanical ventilation in the intensive care unit. The response to therapy was favourable in 25 episodes $(59 \%)$. The crude mortality rate was $40 \%$ (17 of 42) in the cases and 11\% ( 9 of 84) in the controls $(p=0.0002)$. The attributable mortality rate was estimated to be $29 \%(95 \% \mathrm{CI}=16-48 \%)$ while the estimated risk ratio for death was $5.66(95 \%$ $\mathrm{CI}=2.05-15.92$ ).

\section{Discussion}

This prospective study, which covers a period of five years, has identified a total number of 42 cases of
NBP out of 2,373 HIV-infected subjects admitted to a large Italian university hospital with an incidence of 10.8 per 10,000 patient-days. Contrary to what has been reported for NBP in non-HIV-positive immunocompromised patients, the incidence of NBP (and of other infections) has decreased in patients with AIDS receiving HAART in recent in years. In fact, HAART has been shown not only to have a powerful effect on HIV, as shown by the reduction in plasma HIV ribonucleic acid (RNA) and the increase in peripheral T CD4+ cells, but also to reduce the incidence of opportunistic infections (including AIDS-related CNS diseases) and death [12].

In particular, the present study, as a novel observation, provides the "daily rate" of NBP in HIV-infected subjects. This rate can be used to compare the rate of infection between different patient populations and over different periods of time. In practice, nosocomial infections are usually defined as the number of infections acquired during a given time period, divided by the number of hospital admissions over that period. This index is confounded by the duration of hospitalization, and in HIV-infected subjects, by other factors directly related to the use of antiretroviral therapy such as HIV-viraemia and T CD4+ cell count. For this reason, an index previously developed for the analysis of nosocomial infections in elderly patients [17], that controls for the confounding factor of length of stay, was applied. Using this rate, the reduction of NBP in the last two years was confirmed

Step-wise logistic regression analysis indicated that only AIDS-related CNS disease and an increasing APACHE III score were independent risk factors for the onset of NBP in HIV-infected subjects. The presence of an altered neurological status has previously been reported as an important risk factor in casecontrol studies for the development of pneumonia in other immunocompromised patients [18]. The risk of pneumonia is directly related to the possible altered deglutition mechanism. In particular, it has been observed that $70 \%$ of the patients with depressed consciousness can inadvertently aspirate pharyngeal secretions [19]. It is, however, difficult to determine whether the increased risk of NBP in patients with AIDS-related diseases, high APACHE III score and prolonged

Table 2. - Aetiological agents of 42 episodes of nosocomial bacterial pneumonia in human immunodeficiency virusinfected patients and case-fatality rate

\begin{tabular}{lccc}
\hline Agents & Incidence $\%$ & Fatal:nonfatal cases & Case-fatality rate $\%$ \\
\hline Pseudomonas aeruginosa & $9(21)$ & $5: 4$ & 55 \\
Staphylococcus aureus & $7(17)$ & $3: 4$ & 43 \\
Acinetobacter antitratus & $4(9)$ & $1: 3$ & 25 \\
Klebsiella pneumonia & $2(5)$ & $1: 1$ & 50 \\
Escherichia coli & $1(2)$ & $1: 0$ & 100 \\
Enterobacter cloaceae & $1(2)$ & $1: 0$ & 100 \\
Clostridium perfringes & $1(2)$ & $1: 0$ & 100 \\
Proteus mirabilis & $1(2)$ & $1: 0$ & 100 \\
Mixed flora & $2(5)$ & $1: 1$ & 50 \\
Undiagnosed & $14(33)$ & $2: 12$ & 14 \\
Total Gram+ bacteria & $8(19)$ & $4: 4$ & 50 \\
Total Gram- bacteria & $18(43)$ & $10: 8$ & 55 \\
\hline
\end{tabular}

Data are presented as $\mathrm{n}(\%)$. 
hospitalization reflects easier transmission of nosocomial pathogens rather than increased host susceptibility related to severe clinical conditions (high HIV viraemia and low T CD4+ cell count) or whether it is a combination of both these factors.

With regard to aetiology, the present report highlights the importance of $S$. aureus and Pseudomonas aeruginosa as nosocomial pathogens in AIDS patients. Both neutropenia and decreased phagocytosis and bacterial killing, may account for the increased susceptibility of HIV-infected persons to staphylococcal infections. In particular, high nasal colonization of $S$. aureus $(\sim 50 \%)$ has been documented in HIV-infected subjects [20], especially in the advanced stage of HIV disease, with one report [21] suggesting a lower rate in patients who take trimethoprim-sulphamethoxazole as prophylaxis against PCP. The role of $P$. aeruginosa, Klebsiella pneumoniae and Escherichia coli as important agents of severe NBP (often due to antibiotic resistant strains) in patients with HIV infection was confirmed in accordance with other reports [7, 9].

The mean excess length of hospital stay due to NBP was estimated to be 15 days in HIV-infected subjects, with a total excess of 1,213 days over the study period. In HIV-negative patients, the crude mortality rate for NBP has ranged $35-58 \%$, depending on the underlying disease $[1,5]$. In the present study, the crude mortality rate was $40 \%$, while the attributable mortality rate for NBP was estimated to be $29 \%$. The mortality rate, in the authors opinion, was a true reflection of the deaths attributable to NBP, as the matching used in the study allowed control for both the influence of underlying disease category and other confounding variables such as age, sex, duration of hospitalization and number of circulating T CD4+ cells.

To conclude, nosocomial bacterial pneumonia appears to be more common in patients with a high Acute Physiology and Chronic Health Evaluation III score and central nervous system diseases. The present analysis also demonstrates that nosocomial bacterial pneumonia can cause an excess mortality and significantly prolong the hospitalization of human immunodeficiency virus-infected patients. Further studies of targeted interventions may prove to be beneficial in reducing the high risk for nosocomial bacterial pneumonia among acquired immune deficiency syndrome patients. However, the entire scenario of nosocomial infections in human immunodeficiency virus-infected individuals could eventually change as the consequence of the widespread use of highly active antiretroviral therapy.

\section{References}

1. Wenzel RP. Prevention and Control of Nosocomial Infections, 3rd ed. Williams \& Wilkins, Baltimore, 1997.

2. Tumbarello M, Tacconelli E, de Gaetano Donati K. Nosocomial bloodstream infections in HIV infected patients: attributable mortality and extension of hospital stay. J AIDS 1998; 19: 490-497.

3. Selva $J$, Ninivaggi $M$, Toledo A, Forlenza S. Nosocomial infections in HIV infected patients in a large teaching hospital. AJIC 1993; 21: 103-107.
4. Petrosillo N, Pugliese G, Girardi E, et al. Nosocomial infections in HIV infected patients. AIDS 1999; 13: 599-605.

5. Craven DE, Steger KA, La Force FM. Pneumonia. In: Bennett JV, Brachman PS, eds. Hospital Infections, 4th ed. Lippincott-Raven, Philadelphia, 1998; p. 487.

6. Caiaffa WT, Graham NMH, Vlahov D. Bacterial pneumonia in adult populations with human immunodeficiency virus (HIV) infection. Am J Epidemiol 1993; 138: 909-922.

7. Hirschtick RE, Glassroth M, Jordans C. Bacterial pneumonia in persons infected with the human immunodeficiency virus. $N$ Engl J Med 1995; 333: 845851.

8. Tumbarello $\mathrm{M}$, Tacconelli $\mathrm{E}$, de Gaetano $\mathrm{K}$, et al. Bacterial pneumonia in HIV-infected patients. Analysis of risk factors and prognostic indicators. $J$ AIDS 1998; 18: 39-45.

9. Polsky B, Gold JMW, Whimbey E, et al. Bacterial pneumonia in patients with the acquired immunodeficiency syndrome. Ann Intern Med 1986; 104: 38-41.

10. Chaisson RE. Bacterial pneumonia in patients with human immunodeficiency virus infection. Semin Resp Infect 1989; 4: 133-138.

11. Tumbarello M, Tacconelli E, Lucia MB, Cauda R, Ortona L. Predictors of Staphylococcus aureus pneumonia associated with human immunodeficiency virus infection. Respir Med 1996; 90: 531-537.

12. Mouton $\mathrm{Y}$, Alfandari S, Valette $\mathrm{M}$, et al. Impact of protease inhibitors on AIDS-defining events and hospitalizations in 10 French AIDS reference centres. AIDS 1997; 12: F101-F105.

13. Tumbarello M, Tacconelli E, de Gaetano Donati K, Cauda R. HIV-associated bacterial pneumonia in the era of highly active antiretroviral therapy. $J$ AIDS 1999; 20: 208-209.

14. Garner JS, Jarvis WR, Emori TG, Horan TC, Hughes JM. CDC definition for nosocomial infections. Am J Infect Control 1988; 16: 128-140.

15. Center for Disease Control. 1993 revised classification system for HIV infection and expanded surveillance case definition for AIDS among adolescents and adults. $M M W R$ 1992; 41 (RR17): 1-19.

16. Knaus WA, Wagner DP, Draper EA, et al. The APACHE III prognostic system. Risk prediction of hospital mortality for critically ill hospitalized adults. Chest 1991; 100: 1619-1636.

17. Saviteer SM, Samsa GP, Rutala WA. Nosocomial infections in the elderly. Increased risk per hospital day. Am J Med 1988; 84: 661-666.

18. Horkness GA, Bentley DW, Roghmann RI. Risk factors for nosocomial pneumonia in the elderly. Am J Med 1990; 89: 457-463.

19. Huxley EJ, Viroslov J, Gray W, Pierce AK. Pharingeal aspiration in normal adults and patients with depressed consciousness. Am J Med 1978; 64: 564-568.

20. Raviglione MC, Marius P, Pablos-Mendez A, Battan R, Ottuso P, Taranta A. High Staphylococcus aureus nasal carriage rate in patients with acquired immunodeficiency syndrome or AIDS-related complex. Am J Infect Control 1990; 18: 64-69.

21. Weinke T, Schiller R, Fehrenback FJ, Pohle HD. Association between Staphylococcus aureus nasopharingeal colonization and septicemia in patients infected with the human immunodeficiency virus. Eur J Clin Microbiol Infect Dis 1992; 11: 985-989. 